\title{
Additive summation by stimulus compounding irrespective of behavioral contrast during discrimination training: An investigation with positive reinforcement and avoidance schedules
}

\author{
ST ANLEY J. WEISS \\ The American University, Washington, D. C. 20016
}

\begin{abstract}
The similarity in the discrimination training leading to behavioral contrast and that preceding tests producing response enhancement to combined discriminative stimuli suggested that the two phenomena might be related. This was investigated by determining if contrast in discrimination training was necessary for this outcome of stimulus compounding. Responding to tone, light, and to the simultaneous absence of tone and light $(\overline{\mathrm{T}}+\overline{\mathrm{L}})$ was maintained during baseline training by food reinforcement in Experiment I and by shock avoidance in Experiment II. During subsequent discrimination training, responding was reduced in $\bar{T}+\bar{L}$ by programming nonreinforcement in Experiment $I$ and safety or response-punishment in Experiment II. In the first experiment, one rat exhibited positive behavioral contrast, i.e., tone and light rates increased while his $\bar{T}+\bar{L}$ rate decreased. In Experiment II, rats punished in $\bar{T}+\bar{L}$ showed contrast in tone and light, this being the first demonstration of punishment contrast on an avoidance baseline with rats. The discrimination acquisition data are discussed in the light of current explanations of contrast by Gamzu and Schwartz (1973) and Terrace (1972). During stimulus compounding tests, all subjects in both experiments emitted more responses to tone-plus-light than to tone or light (additive summation). An analysis of the terminal training baselines suggests that the factors producing these test results seem unrelated to whether or not contrast occurred during discrimination training. It was concluded that the stimulus compounding test reveals the operation of the terminal baseline response associations and reinforcement associations conditioned on these multicomponent free-operant schedules of reinforcement.
\end{abstract}

Additive summation refers to an increase in responding to the simultaneous presentation of two independently conditioned discriminative stimuli relative to that controlled by either stimulus presented alone. Weiss (1971, Experiment 1) has shown, however, that separate experience with the two stimuli ultimately compounded is, in itself, insufficient to produce additive summation when these stimuli are later presented simultaneously. Rats were trained on a two-component multiple schedule where responding during a tone produced food on the average of every $30 \mathrm{sec}$ [variable interval (VI) $30 \mathrm{sec}$ ] while responding in light produced food every $120 \mathrm{sec}$, on the average. Responding to tone plus light in a later test was intermediate between the levels of responding to tone and light presented separately. The major procedural difference between the two-component multiple schedules of that experiment and the three-component schedules of experiments reporting additive summation was that in the latter experiments extinction was associated with the simultaneous absence of the positive discriminative stimuli.

This research was supported by Grant MH-16853 trom the National Institute of Mental Health, United States Public Health Service. It was presented at the castern Prychological Aesociation Convention. Philadelphia. Pa., 1974. The author appreciates the efforts of Dr. Alan silberberg in his critical reading of this manuscript. Reprints may be obtained from the author, Department of Psycholoty. The American University, Wash ington, D.C. 20016.
The incorporation of extinction training during the absence of tone and light $(\bar{T}+\bar{L})$ in those studies reporting additive summation to tone plus light $(T+L)$ caused $\bar{T}+\bar{L}$ (a) to control lower response rates than either of the VI associated tone or light discriminative stimuli ( $\mathrm{SD}_{\mathrm{S}}$ ), and also (b) to signal a period of reduced reinforcement. When Weiss (1971, Experiment II) separated the contribution of these two factors to the outcome of stimulus compounding he concluded "...that the response differentiation, as well as the nonreinforcement consequences of $S \Delta$ training, contribute to the magnitude of response enhancement to compound SD" (p. 396, italics added).

The discrimination training employed in most studies reporting additive summation, where tone as well as light maintain responding with food reinforcement while responding is extinguished in $\overline{\mathrm{T}}+\overline{\mathrm{L}}$, appears essentially similar to the discrimination training investigated by Reynolds (1961). Reynolds initially maintained keypecking in pigeons to red and green keys by associating both with a VI 180-sec schedule of food reinforcement. Subsequently, he stopped reinforcing the pigeons when the key was green, while keeping the VI schedule operative while it was red. He noted that as the pigeon's response rate decreased in the extinguished component, rate in the unchanged red key component increased over that maintained when responding was reinforced on both keys. Reynolds called this interaction behavioral contrast. Freeman (1971a) concluded her 


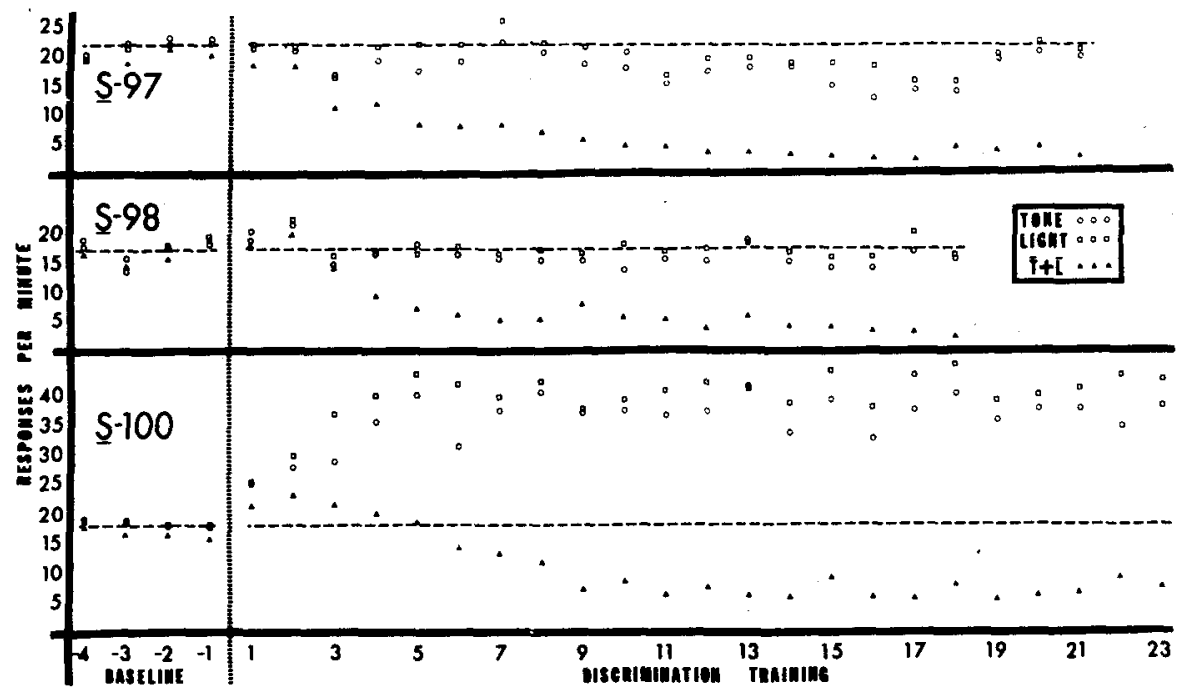

Figure 1. Response rates to tone, light, and $\bar{T}+\overline{\mathbf{L}}$ during baseline (left) and discrimination training phases of Experiment $\mathrm{I}$. The horizontal dashed line in each frame projects the tone and light baseline reference rates over the discrimination training sessions. All points represent combined data for two consecutive sessions (Note that the stight rate increase during all stimuli - tone, light, and $T+\bar{L}$ - occurring at Discrimination Training Points 1 and 2 for $S 98$ is not a differentiated contrast effect.)

review of the contrast literature by pointing out that "Contrast occurs when the relative frequency of reinforcement is altered and when responding is suppressed in one component of a multiple schedule. While both of these conditions are sufficient to produce contrast, it has not been clearly demonstrated that either of these two variables alone provides the necessary conditions." (p. 354).

Additive summation has been reported on stimulus compounding tests performed after discriminations have stabilized following extensive baseline training, while contrast is measured during discrimination training. A comparison of training procedures and research to date suggests, however, that similar variables might be involved in both phenomena. Freeman (1971a) and Weiss (1971) referred to procedures that reduce the response rate and reinforcement frequency in the altered schedule component during discrimination as contributing to contrast and the results of stimulus compounding, respectively. This could suggest that contrast and additive summation are closely related.

On those baselines preceding stimulus compounding tests yielding additive summation (see Weiss, 1972, for a review), responding in $\overline{\mathrm{T}}+\overline{\mathrm{L}}$ is usually reduced through a reinforcement manipulation while responding is maintained in tone and light with reinforcement. What happens to response rate in tone, light, and $\overline{\mathrm{T}}+\overline{\mathrm{L}}$ during the acquisition of these discriminations, prior to the baseline stabilization preceding the stimulus compounding test, has not been studied. However, following Freeman's conclusions, behavioral contrast durng tone and light might be anticipated during this discrimination training.

The present series of experiments measured the time course of the acquisition of the tone, light, and $\overline{\mathrm{T}}+\overline{\mathrm{L}}$ discriminations preceding a stimulus compounding test. Then, using this acquisition data, it was determined if there was any relationship between the occurrence of behavioral contrast to tone and light during discrimination training, when responding to $\overline{\mathrm{T}}+\overline{\mathrm{L}}$ was reduced, and the magnitude of additive summation to tone plus light during stimulus compounding. Experiment I pursued this investigation when responding to tone and light was maintained by positive reinforcement, and Experiment II when it was maintained by free-operant shock avoidance.

\section{EXPERIMENT I}

\section{Method}

Subjects. Three naive male hooded rats served. They were maintained at $80 \%$ of their approximately $350 \mathrm{~g}$ free feeding weights.

Apparatus. The operant training chamber measured 8 in. high, 8.25 in. long, and 7 in. wide ( 20 by 21 by $17.5 \mathrm{~cm})$. Its side walls were white translucent plastic, its front and rear walls aluminum, and its ceiling perforated clear plastic. The chamber floor was composed of stainless steel rods. A microswitch manipulandum and food trough were mounted on the front wall. The tone was $2000 \mathrm{~Hz}$ at $90-95 \mathrm{~dB}$, and the ambient noise level, with the exhaust fan on, was $80 \mathrm{~dB}$. The light $\mathrm{S}^{\mathrm{D}}$, generated by two $25-\mathrm{W} 120-\mathrm{V}$ butbs, was $130.2 \mathrm{~cd} / \mathrm{m}^{2}$. A dim houselight was on continuously. Apparatus and stimuli are described in greater detail elsewhere (Emurian \& Weiss, 1972).

Solid state programming equipment was located in a room adjacent to that housing the training chambers. Reinforcers were Noyes $45-\mathrm{mg}$ rat pellets.

Procedure. Baseline training. The rats were initially trained to approach the food trough when the feeder was operated. They were then trained, through successive approximation, to press the bar on a continuous reinforcement schedule. This was gradually changed, over sessions, to a variable interval (VI) 
60-sec schedule where a pellet was produced by a barpress on the average of only once a minute. The limits of this VI schedule were 2 and $240 \mathrm{sec}$, with intervals sequenced so as to have the duration of any interval independent of the preceding interval. During baseline training, the VI $60-\mathrm{sec}$ schedule was operating during tone, light, and tone-off light-out $\overline{(\mathrm{T}}+\overline{\mathrm{L})}$ components. $\overline{\mathrm{T}}+\overline{\mathrm{L}}$ separated the former components, which were sequenced to prevent any one from following $\overline{\mathrm{T}}+\overline{\mathrm{L}}$ more than three times in succession. These components averaged approximately $3.5 \mathrm{~min}$ within the limits of 2 and $5 \mathrm{~min}$. Sessions lasted about $2 \mathrm{~h}$. Subjects 97,98 , and 100 received 21,25 , and 21 baseline sessions, respectively.

Discrimination training. When responding stabilized on the nondifferential baseline schedule, discrimination training was begun. This consisted of approximately $403-\mathrm{h}$ sessions during which the VI 60-sec schedule remained effective in tone as well as light while reinforcement was discontinued (S $\Delta)$ in $T+\bar{L}$. Stimulus sequence as well as the duration of tone and light components remained the same as in baseline training. During initial discrimination sessions, $\overline{\mathrm{T}}+\overline{\mathrm{L}}$ duration was set within the limits of 20 to $50 \mathrm{sec}$, varied within and between sessions, with the upper limit gradually extended to $90 \mathrm{sec}$ as training progressed. A response correction contingency operated during $\overline{\mathrm{T}}+\overline{\mathrm{L}}$ to cause a response to reset the component duration timer.

Testing. When the discrimination appeared to stabilize, a stimulus compounding test was administered. This contained 18 block-randomized replications of 45 -sec presentations of tone, light, and tone plus light $(T+L)$. These stimuli were each separated by 15 sec of $\bar{T}+\bar{L}$. Testing started after a subject received approximately 30 reinforcements on his terminal training schedule. Reinforcement was discontinued during the test.

\section{Results}

Figure 1 gives terminal baseline and discrimination training response rates to tone, light, and $\overline{\mathrm{T}}+\overline{\mathrm{L}}$. It shows that (1) all subjects formed the discrimination by the 40th session, responding at higher rates to tone and to light than to $\overline{\mathrm{T}}+\overline{\mathrm{L}}$; and (2) only $\mathrm{S} 100$ exhibited any transition behavior that could be considered contrast. Nevertheless, the stimulus compounding test data of Table 1 unequivocally reveal that all rats showed additive summation to $\mathrm{T}+\mathrm{L}$, each emitting well over $50 \%$ of his test responses to this test condition.

\section{EXPERIMENT II}

The training and testing format of this experiment was basically similar to that of Experiment I, with the exception that responding was maintained by free-operant avoidance (FOA) schedules rather than positive reinforcement. [On a FOA schedule, a response postpones shock for a specified time, the response-shock (RS) interval, while in the absence of responding shocks are presented at a rate determined by the shock-shock (SS) interval.] For 5 of the 11 subjects responding was reduced in $\overline{\mathrm{T}}+\overline{\mathrm{L}}$ through extinction. That is, the FOA schedule was removed. To encourage contrast during discrimination training in tone and light, the remaining subjects also had response-punishment scheduled in $\bar{T}+\bar{L}-a$ procedure that was reported to produce punishment contrast with monkeys on an avoidance baseline by Lattal and Griffin (1972).

\section{Method}

Subjects. Eleven male hooded rats, approximately $350-400 \mathrm{~g}$ at the start of Experiment II, were maintained with free access to food and water in their home cages. Prior to the manipulations reported here, these subjects participated in another experiment in which they were trained for approximately $30-35$ 8-h sessions on a baseline schedule that had RS10-sec SS $5-\sec$ FOA operating in $\bar{T}+\bar{L}$ and RS $25-\sec$ SS 5 -sec effective in tone as well as light. This conditioned most subjects to respond at about twice the rate in $\bar{T}+\bar{L}$ as tone or light. These rates, which will serve as the referents for the manipulations of the current experiment, are given in the baseline column of Table 2 .

Apparatus. This was the same as used in Experiment i. Constant current shock was generated by a Lehigh Valley Electronics 1531 shocker and delivered to the grid floor, manipulandum, and front and rear walls through its associated scrambler.

Proced ure. $\bar{T}+\bar{L}$ response-reduction training. The avoidance contingency was discontinued during $\bar{T}+\bar{L}$ while the RS 25 -sec SS 5-sec FOA schedule remained in effect during tone as well as light. The components averaged $6 \mathrm{~min}$ in length, the limits being 2 and $10 \mathrm{~min}$. Duration of $\bar{T}+\bar{L}$ was programmed for the maximum duration during initial transition sessions in order that

Table 1

Stimulus Compounding Test Results of Experiment I: Total Responses

\begin{tabular}{|c|c|c|c|c|c|c|c|c|c|c|c|c|}
\hline \multirow{2}{*}{$\begin{array}{l}\text { Test } \\
\text { Reps }\end{array}$} & \multicolumn{4}{|c|}{$\begin{array}{c}\text { Subject } 97 \\
\text { Stimulus Conditions }\end{array}$} & \multicolumn{4}{|c|}{$\begin{array}{c}\text { Subject } 98 \\
\text { Stimulus Conditions } \\
\end{array}$} & \multicolumn{4}{|c|}{$\begin{array}{c}\text { Subject } 100 \\
\text { Stimulus Conditions }\end{array}$} \\
\hline & $\overline{\mathrm{T}}+\overline{\mathrm{L}}$ & Tone & Light & $T+L$ & $\overline{\mathrm{T}}+\overrightarrow{\mathrm{L}}$ & Tone & Light & $T+L$ & $\overline{\mathrm{T}}+\overline{\mathrm{L}}$ & Tone & Light & $\mathrm{T}+\mathrm{L}$ \\
\hline $1-3$ & 9 & 43 & 65 & 81 & 29 & 26 & 52 & 48 & 19 & 69 & 85 & 106 \\
\hline $4-6$ & 1 & 34 & 44 & 58 & 9 & 31 & 28 & 54 & 5 & 27 & 79 & 116 \\
\hline $7-9$ & 3 & 17 & 33 & 51 & 5 & 8 & 12 & 27 & 4 & 3 & 44 & 77 \\
\hline $10-12$ & 0 & 0 & 23 & 56 & 4 & 12 & 6 & 36 & 3 & 1 & 15 & 37 \\
\hline $13-15$ & 0 & 1 & 5 & 26 & 2 & 7 & 7 & 34 & 0 & 3 & 24 & 74 \\
\hline $16-18$ & 0 & 0 & 2 & 46 & 1 & 9 & 3 & 24 & 0 & 0 & 2 & 56 \\
\hline $\begin{array}{l}\text { Total } \\
\text { Test }\end{array}$ & 13 & 95 & 172 & 318 & 50 & 95 & 108 & 223 & 31 & 103 & 249 & 466 \\
\hline $\begin{array}{l}\text { Percent } \\
\text { Test Rs }\end{array}$ & & 16.2 & 29.4 & 54.4 & & 22.3 & 25.3 & 52.4 & & 12.6 & 30.4 & 57.0 \\
\hline
\end{tabular}


Table 2

Baseline and Initial $\overline{\mathbf{T}}+\overline{\mathbf{L}}$ Extinction Sessions: Responses Per Minute

\begin{tabular}{|c|c|c|c|c|c|c|c|c|c|c|}
\hline \multirow[b]{2}{*}{ Subject } & \multicolumn{3}{|c|}{ Baseline . Sessions* } & \multicolumn{7}{|c|}{ Initial $\overline{\mathrm{T}}+\overline{\mathrm{L}}$ Extinction Sessions in Quintiles** } \\
\hline & Schedule & Mean & SD & Schedule & 1 & 2 & 3 & 4 & 5 & $\begin{array}{c}\text { Sessions } \\
\text { Presented }\end{array}$ \\
\hline 121 & $\begin{array}{l}\text { RS } 25 \dagger \\
\text { RS } 10 \dagger \dagger\end{array}$ & $\begin{array}{l}11.8 \\
21.7\end{array}$ & $\begin{array}{l}.4 \\
.9\end{array}$ & $\begin{array}{l}\text { RS } 25 \dagger \\
\text { Extinction } \dagger \dagger\end{array}$ & $\begin{array}{r}14.5 \\
8.3\end{array}$ & $\begin{array}{r}11.9 \\
5.5\end{array}$ & $\begin{array}{r}11.8 \\
4.7\end{array}$ & $\begin{array}{r}10.9 \\
6.6\end{array}$ & $\begin{array}{r}10.8 \\
3.9\end{array}$ & 10 \\
\hline 123 & $\begin{array}{l}\text { RS } 25 \\
\text { RS } 10\end{array}$ & $\begin{array}{r}8.2 \\
16.2\end{array}$ & $\begin{array}{r}.3 \\
1.0\end{array}$ & $\begin{array}{l}\text { RS } 25 \\
\text { Extinction }\end{array}$ & $\begin{array}{l}9.0 \\
9.3\end{array}$ & $\begin{array}{l}9.2 \\
6.9\end{array}$ & $\begin{array}{l}9.2 \\
5.6\end{array}$ & $\begin{array}{l}9.4 \\
4.8\end{array}$ & & 4 \\
\hline 130 & $\begin{array}{l}\text { RS } 25 \\
\text { RS } 10\end{array}$ & $\begin{array}{l}10.2 \\
17.9\end{array}$ & $\begin{array}{r}.5 \\
1.6\end{array}$ & $\begin{array}{l}\text { RS } 25 \\
\text { Extinction }\end{array}$ & $\begin{array}{l}9.2 \\
5.9\end{array}$ & $\begin{array}{l}9.8 \\
5.2\end{array}$ & $\begin{array}{r}10.2 \\
4.0\end{array}$ & $\begin{array}{r}10.2 \\
3.3\end{array}$ & $\begin{array}{r}10.3 \\
2.9\end{array}$ & 9 \\
\hline 135 & $\begin{array}{l}\text { RS } 25 \\
\text { RS } 10\end{array}$ & $\begin{array}{r}9.8 \\
19.1\end{array}$ & $\begin{array}{l}1.0 \\
1.3\end{array}$ & $\begin{array}{l}\text { RS } 25 \\
\text { Extinction }\end{array}$ & $\begin{array}{l}9.5 \\
7.8\end{array}$ & $\begin{array}{l}9.5 \\
5.7\end{array}$ & $\begin{array}{l}9.2 \\
4.1\end{array}$ & $\begin{array}{r}10.3 \\
3.6\end{array}$ & $\begin{array}{r}10.0 \\
2.8\end{array}$ & 9 \\
\hline 137 & $\begin{array}{l}\text { RS } 25 \\
\text { RS } 10\end{array}$ & $\begin{array}{r}8.7 \\
11.7\end{array}$ & $\begin{array}{l}.2 \\
.6\end{array}$ & $\begin{array}{l}\text { RS } 25 \\
\text { Extinction }\end{array}$ & $\begin{array}{l}8.4 \\
6.5\end{array}$ & $\begin{array}{l}9.2 \\
3.5\end{array}$ & $\begin{array}{l}8.6 \\
2.1\end{array}$ & $\begin{array}{l}8.4 \\
1.4\end{array}$ & $\begin{array}{l}9.1 \\
1.4\end{array}$ & 26 \\
\hline 138 & $\begin{array}{l}\text { RS } 25 \\
\text { RS } 10\end{array}$ & $\begin{array}{r}7.5 \\
14.7\end{array}$ & $\begin{array}{r}.5 \\
1.0\end{array}$ & $\begin{array}{l}\text { RS } 25 \\
\text { Extinction }\end{array}$ & $\begin{array}{l}9.3 \\
2.9\end{array}$ & $\begin{array}{l}7.4 \\
1.2\end{array}$ & $\begin{array}{l}8.1 \\
1.9\end{array}$ & $\begin{array}{l}7.7 \\
2.1\end{array}$ & $\begin{array}{l}7.6 \\
2.3\end{array}$ & 6 \\
\hline 139 & $\begin{array}{l}\text { RS } 25 \\
\text { RS } 10\end{array}$ & $\begin{array}{r}5.4 \\
10.6\end{array}$ & $\begin{array}{r}.2 \\
1.1\end{array}$ & $\begin{array}{l}\text { RS } 25 \\
\text { Extinction }\end{array}$ & $\begin{array}{l}6.6 \\
1.5\end{array}$ & $\begin{array}{l}6.5 \\
2.1\end{array}$ & $\begin{array}{l}5.7 \\
1.1\end{array}$ & & & 3 \\
\hline 147 & $\begin{array}{l}\text { RS } 25 \\
\text { RS } 10\end{array}$ & $\begin{array}{r}6.1 \\
13.0\end{array}$ & $\begin{array}{l}.4 \\
.9\end{array}$ & $\begin{array}{l}\text { RS } 25 \\
\text { Extinction }\end{array}$ & $\begin{array}{l}5.7 \\
1.2\end{array}$ & $\begin{array}{l}4.5 \\
1.6\end{array}$ & $\begin{array}{l}6.1 \\
1.7\end{array}$ & & & 3 \\
\hline 149 & $\begin{array}{l}\text { RS } 25 \\
\text { RS } 10\end{array}$ & $\begin{array}{r}5.4 \\
10.9\end{array}$ & $\begin{array}{l}.3 \\
.4\end{array}$ & $\begin{array}{l}\text { RS } 25 \\
\text { Extinction }\end{array}$ & $\begin{array}{l}6.6 \\
4.2\end{array}$ & $\begin{array}{l}6.5 \\
3.2\end{array}$ & $\begin{array}{l}6.3 \\
3.8\end{array}$ & $\begin{array}{l}8.1 \\
2.6\end{array}$ & $\begin{array}{l}6.1 \\
2.2\end{array}$ & 5 \\
\hline 150 & $\begin{array}{l}\text { RS } 25 \\
\text { RS } 10\end{array}$ & $\begin{array}{r}9.8 \\
14.9\end{array}$ & $\begin{array}{l}.5 \\
.4\end{array}$ & $\begin{array}{l}\text { RS } 25 \\
\text { Extinction }\end{array}$ & $\begin{array}{l}8.5 \\
7.7\end{array}$ & $\begin{array}{l}7.6 \\
7.1\end{array}$ & $\begin{array}{l}9.0 \\
4.2\end{array}$ & $\begin{array}{l}7.5 \\
3.8\end{array}$ & $\begin{array}{l}7.2 \\
2.0\end{array}$ & 8 \\
\hline 151 & $\begin{array}{l}\text { RS } 25 \\
\text { RS } 10\end{array}$ & $\begin{array}{r}9.5 \\
17.3\end{array}$ & $\begin{array}{r}.7 \\
1.5\end{array}$ & $\begin{array}{l}\text { RS } 25 \\
\text { Extinction }\end{array}$ & $\begin{array}{r}9.0 \\
10.0\end{array}$ & $\begin{array}{l}8.6 \\
6.3\end{array}$ & $\begin{array}{l}9.5 \\
4.3\end{array}$ & $\begin{array}{l}7.8 \\
2.4\end{array}$ & $\begin{array}{l}8.0 \\
2.7\end{array}$ & 11 \\
\hline
\end{tabular}

*Calculated from response rates of final four sessions on indicated baseline schedule.

**These entries are daily session data when five or fewer sessions are presented. With more than five sessions, each entry represents approximately a fifth of the sessions presented. Thus, each entry represents two sessions for Subject 121, while for Subject 130, four entries represent the mean of two sessions and one entry, randomly selected, presents the data from a single session.

tSignaled by tone as well as light. Entries represent the average of tone and light rates.

t+Signaled by $\bar{T}+\bar{L}$.

the subjects might better come in contact with the extinction (safety) effective during this stimulus. Stimulus sequencing was the same as that of Experiment I, with sessions approximately $8 \mathrm{~h}$ long. Subjects were trained on alternate days.

The subjects were nonsy stematically assigned to either a group run with extinction scheduled in $\bar{T}+\bar{L}$ or with response punishment effective in $\bar{T}+\overline{\mathrm{L}}$. These groups will be referred to as "extinction" and "punishment" groups, respectively. In order that response punishment in $\overline{\mathrm{T}}+\overline{\mathrm{L}}$ not be overly disruptive, it was not instituted until $\overline{\mathrm{T}}+\overline{\mathrm{L}}$ rate had declined to roughly $25 \%$ of that in tone and light through the extinction programmed in $\overline{\mathrm{T}}+\overline{\mathrm{L}}$. After several response-punishment sessions, the punishment was put on a $50 \%$ schedule for all punishment subjects except $S 151$. (The introduction of the response-punishment contingency in $\bar{T}+\overline{\mathrm{L}}$ severely disrupted avoidance responding in tone and light for $S 151$. After four sessions on this schedule, punishment was removed from $\bar{T}+\bar{L}$ so that he might regain avoidance proficiency. Thereafter response-punishment was successfully reinstituted in $\bar{T}+\overline{\mathrm{L}}$, but only $20 \%$ of his responses resulted in shock.)

A subject was trained until his cumulative records indicated, after a 1-h warm-up, four consecutive sessions of immediate and sustained (1) rate increase, prior to shock, in at least $75 \%$ of the tone and the light components, and (2) rate decrease in at least $75 \%$ of the $\overline{\mathrm{T}}+\overline{\mathrm{L}}$ components. Subjects 135,147 , and 150 received 20,13 , and $36 \overline{\mathrm{T}}+\overline{\mathrm{L}}$ extinction sessions, respectively. The number of extinction/punishment sessions received by
Subjects $121,123,130,137$, and 151 were, respectively, 13/9, $7 / 9,12 / 8,30 / 8$, and $14 / 26$. Three subjects $(138,139$, and 149) were eliminated because, after extensive training, they were not making progress towards satisfying Criterion 1 . That is, they usually did not begin responding when the tone or light came on until they had received a shock prompt. ${ }^{1}$

Stimulus compounding test. This extinction test consisted of 12 block-randomized replications of 2 -min presentations of tone, light, and $\mathrm{T}+\mathrm{L}$ stimulus conditions where each test stimulus was followed by 2 min of $\bar{T}+\bar{L}$. However, to maintain responding better during the test there were brief reacquisition periods after Test Replications 4 and 8 . During a reacquisition period, where tone and light were each presented once, the terminal training contingencies were operating during tone, light, and $\bar{T}+\overline{\mathrm{L}}$. Testing started after a rat had received approximately a 1-h warm-up on his terminal training schedule.

\section{Results}

Baseline and initial transition performance. The baseline response rates presented in Table 2 illustrate the behavioral stability of each subject prior to the $\overline{\mathrm{T}}+\overline{\mathrm{L}}$ manipulations. In all cases, for tone, light, and $\bar{T}+\bar{L}$ rates, the between-session variability represented by the standard deviation is less than $10 \%$ of the mean baseline session response rates. 
The initial transition session data presented in Table 2 show that the $\overline{\mathrm{T}}+\overline{\mathrm{L}}$ response rates systematically decreased over these sessions for all 11 subjects. The rates in RS $25-\mathrm{sec}$ SS $5-\mathrm{sec}$ associated tone and light changed unsystematically over subjects. These rates remained essentially unchanged, or decreased, for Subjects $130,135,137,147,150$, and 151. Only Subjects 123 and 149 exhibited a sustained response increase over these sessions during their RS 25-sec SS 5-sec associated stimuli.

Averaged Table 2 data are plotted in Figure 2. It is obvious that mean avoidance rates in tone and light were unchanged between the baseline sessions and these initial $\overline{\mathrm{T}}+\overline{\mathrm{L}}$ extinction sessions $[\mathrm{F}(5 / 50)=0.71, \mathrm{p}>$.5] while $\overline{\mathrm{T}}+\overline{\mathrm{L}}$ rate decreased significantly $[\mathrm{F}(5 / 50)=120.0$, $p<.001]$. A Neuman-Keuls procedure indicated that $\overline{\mathrm{T}}+\overline{\mathrm{L}}$ rates (1) during baseline were higher than in Extinction Quintiles 1, 2, 3, 4, or $5(\mathrm{p}<.01)$; (2) in Quintile 1 were significantly higher than in $2(\mathrm{p}<.05)$, 3 , 4 , or $5(p<.01)$; and $(3)$ in Quintile 2 were significantly higher than in $5(\mathrm{p}<.01)$.

Punishment performance. The discriminations between tone, light, and $\bar{T}+\bar{L}$ were comparable over the baseline sessions presented in Figure $3 \mathrm{~A}$ and those in Figure 3B. Over these sessions $\bar{T}+\overline{\mathrm{L}}$ controlled $24.7 \%$ of the averaged tone and light rates for the subjects of Figure $3 \mathrm{~A}$ and $22.6 \%$ for those in Figure 3B $[t(9)=0.47, .7>p>.6]$. Programming response-punishment in $\bar{T}+\overline{\mathrm{L}}$ significantly reduced response rate in that component an average of $71.1 \%$ between the three prepunishment and the four initial-punishment sessions presented in Figure $3 \mathrm{~A}$ $[\mathrm{t}(5)=4.99, \mathrm{p}<.01]$. In comparison, the mean $20.5 \%$ rate reduction in $\overline{\mathrm{T}}+\overline{\mathrm{L}}$ between the prepunishment subject-matched sessions and the continued extinction

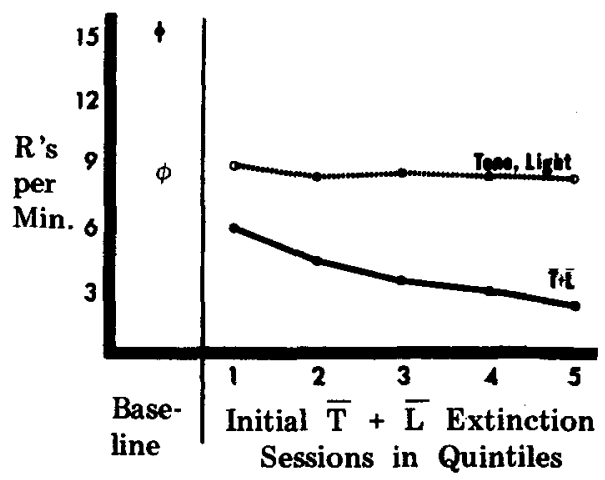

Figure 2. Averaged response rates of Table 2 over baseline and initial $T+L$ extinction sessions. Free-operant avoidance (RS 25-sec SS 5-sec) was effective in tone and light over all sessions. In $\overline{\mathbf{T}}+\overline{\mathbf{L}}$ RS 10 -sec SS 5 -sec operated through the baseline sessions and was removed during the extinction sessions. Mean between baseline session variability, as represented by the standard deviation, is given by the vertical lines through baseline points. (To have all subjects represented at each point, if a value was not entered in Table 2 it was taken from the data of that subject in Figure 3.)

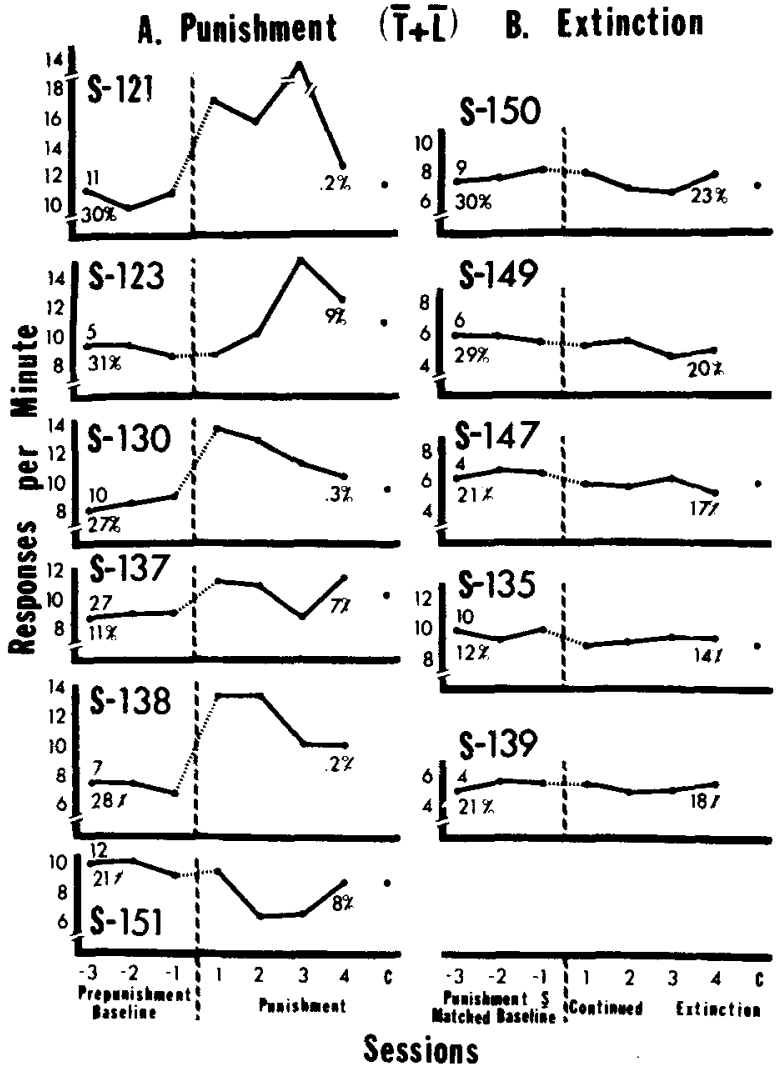

Figure 3. Averaged tone and light avoidance rates for $\overline{\mathbf{T}}+\overline{\mathrm{L}}$ punishment (A) and extinction (B) subjects of Experiment Il. In A, the three points to the left of the broken line in each frame present RS 25 -sec avoidance rates during prepunishment baseline sessions, and the four connected points to the right, avoidance rates during $\bar{T}+\bar{L}$ Punishment Sessions 1-4. In B, the three points to the left are RS 25-sec avoidance rates, approximately matched with punishment subjects across rows for $\overline{\mathbf{T}}+\overline{\mathbf{L}}$ discriminative performance. Avoidance performance when extinction was continued in $\overline{\mathbf{T}}+\overline{\mathbf{L}}$ is shown to the right of the broken line in Column B. The number on the left in all frames, above the response curves, indicates the first of the consecutive discrimination training sessions presented, the preceding sessions being given in Table 2 . The numbers below the curves give the $\bar{T}+\bar{L}$ rate for the baseline and punishment (A) or continued extinction (B) sessions as a percentage of tone and light rates. Point $C$ gives the mean criterion RS 25-sec avoidance rates, from Table 3, of those subjects satisfying the discrimination criteria of Experiment IL.

sessions of the rats in Figure $3 \mathrm{~B}$ did not reach significance $[t(4)=2.13, p=.1]$. As this would imply, the percentage rate decrease in $\bar{T}+\bar{L}$ was significantly greater for the punishment group than that for the extinction group $[t(9)=2.60, p<.05]$. Simultaneously, punishment in $\bar{T}+\bar{L}$ had a profound effect on the avoidance rates in tone and light where the schedule remained unchanged.

Response-shock 25-sec SS 5-sec avoidance rates during the three prepunishment and four initial punishment training sessions are shown for individual subjects in the frames of Figure $3 \mathrm{~A}$. The avoidance rates in tone as well as light increased dramatically when responding in $\bar{T}+\bar{L}$ was punished for all subjects but S 151, whose behavior 
Table 3

Responses Per Minute Computed from Four Criterion Sessions Prior to Testing: Experiment II

\begin{tabular}{|c|c|c|c|c|}
\hline \multirow[b]{2}{*}{ Subject } & & \multicolumn{3}{|c|}{ Stimulus Conditions } \\
\hline & & $\overline{\mathrm{T}}+\overline{\mathrm{L}}$ & Tone & Light \\
\hline \multicolumn{5}{|c|}{$\overline{\mathrm{T}}+\overline{\mathrm{L}}$ Punishment Group } \\
\hline 121 & $\begin{array}{l}\text { Mean } \\
\text { SD }\end{array}$ & $\begin{array}{l}.1 \\
.1\end{array}$ & $\begin{array}{r}11.1 \\
.9\end{array}$ & $\begin{array}{r}11.1 \\
1.0\end{array}$ \\
\hline 123 & $\begin{array}{l}\text { Mean } \\
\text { SD }\end{array}$ & $\begin{array}{l}.1 \\
.1\end{array}$ & $\begin{array}{r}11.6 \\
1.4\end{array}$ & $\begin{array}{r}9.8 \\
.6\end{array}$ \\
\hline 130 & $\begin{array}{l}\text { Mean } \\
\text { SD }\end{array}$ & $\begin{array}{l}.1 \\
.0\end{array}$ & $\begin{array}{r}9.3 \\
.9\end{array}$ & $\begin{array}{l}9.7 \\
1.1\end{array}$ \\
\hline 137 & $\begin{array}{l}\text { Mean } \\
\text { SD }\end{array}$ & $\begin{array}{l}.3 \\
.1\end{array}$ & $\begin{array}{l}9.8 \\
1.3\end{array}$ & $\begin{array}{r}10.7 \\
.6\end{array}$ \\
\hline 151 & $\begin{array}{l}\text { Mean } \\
\text { SD }\end{array}$ & $\begin{array}{l}.1 \\
.0\end{array}$ & $\begin{array}{r}8.3 \\
.7\end{array}$ & $\begin{array}{r}9.1 \\
.5\end{array}$ \\
\hline Mean & $\begin{array}{l}\text { Mean } \\
\text { SD }\end{array}$ & $\begin{array}{l}.1 \\
.1\end{array}$ & $\begin{array}{r}10.0 \\
1.0\end{array}$ & $\begin{array}{r}10.1 \\
.8\end{array}$ \\
\hline \multicolumn{5}{|c|}{$\overrightarrow{\mathrm{T}}+\overrightarrow{\mathrm{L}}$ Extinction Group } \\
\hline 135 & $\begin{array}{l}\text { Mean } \\
\text { SD }\end{array}$ & $\begin{array}{l}.6 \\
.2\end{array}$ & $\begin{array}{r}8.4 \\
.5\end{array}$ & $\begin{array}{r}9.2 \\
.6\end{array}$ \\
\hline 147 & $\begin{array}{l}\text { Mean } \\
\text { SD }\end{array}$ & $\begin{array}{l}.6 \\
.2\end{array}$ & $\begin{array}{r}5.7 \\
.2\end{array}$ & $\begin{array}{r}6.0 \\
.9\end{array}$ \\
\hline 150 & $\begin{array}{l}\text { Mean } \\
\text { SD }\end{array}$ & $\begin{array}{r}1.0 \\
.2\end{array}$ & $\begin{array}{r}7.1 \\
.2\end{array}$ & $\begin{array}{r}7.0 \\
.2\end{array}$ \\
\hline Mean & $\begin{array}{l}\text { Mean } \\
\text { SD }\end{array}$ & $\begin{array}{l}.7 \\
.2\end{array}$ & $\begin{array}{r}7.1 \\
.3\end{array}$ & $\begin{array}{r}7.4 \\
.6 \\
\end{array}$ \\
\hline
\end{tabular}

was generally disrupted. This average $33.8 \%$ increase in tone and light rates between the three pre- and four initial punishment sessions yielded a $t(5)=2.45$, just 0.12 shy of significance at $p=.05$.

The avoidance rates of those subjects remaining on extinction in $\overline{\mathrm{T}}+\overline{\mathrm{L}}$ are shown in the frames of Figure 3B during sessions comparable to those presented for the punishment subjects. The baselines of the extinction subjects are approximately matched across rows in Figure 3 with punishment subjects in regard to (a) $\overline{\mathrm{T}}+\overline{\mathrm{L}}$ to tone and light response rate discriminations during the prepunishment baseline sessions and also, where possible, (b) the number of $\overline{\mathrm{T}}+\overline{\mathrm{L}}$ extinction discrimination sessions to the final baseline session. Avoidance rate decreased between baseline and continued $\overline{\mathrm{T}}+\overline{\mathrm{L}}$ extinction sessions for all subjects in Figure $3 \mathrm{~B}$, the mean $9.6 \%$ decrease being significant $[\mathrm{t}(4)=10.6, \mathrm{p}<.01]$. Comparing these percent changes in avoidance rate between groups showed them to be significantly different $[\mathrm{t}(9)=3.0, \mathrm{p}<.02]$.

Criterion performance. Discrimination criterion session data are given in Table 3 . As would be expected, the subjects receiving punishment in $\bar{T}+\bar{L}$ for responding have a significantly lower $\overline{\mathrm{T}}+\overline{\mathrm{L}}$ rate than those whose responses were only extinguished during this stimulus $[\mathrm{t}(6)=4.25, \mathrm{p}<.01]$. This difference varies inversely with a difference in avoidance response rates between groups. The 10.1 responses/min criterion avoidance rate of the $\bar{T}+\bar{L}$ punishment subjects is significantly higher than the 7.3 responses $/ \mathrm{min}$ avoidance rate of the extinction group $[t(6)=3.33$, $\mathrm{p}<.02]$, while the baseline avoidance rates presented in Table 2 did not differ between these groups, being 9.7 and 8.6 responses/min respectively $[\mathrm{t}(6)=0.68$, $.6>p>.5]$. Although the mean avoidance rates of the $\overline{\mathrm{T}}+\mathrm{L}$ punishment group did not change between Table 2 baseline sessions and Table 3 criterion sessions, being 9.7 and 10.1 responses/min respectively, it appears that the punishment contingency effective in $\overline{\mathrm{T}}+\mathrm{L}$ tended to keep tone and light avoidance rates from falling below their baseline levels for the group as a whole. The tone and light criterion avoidance rates of $\overline{\mathrm{T}}+\overline{\mathrm{L}}$ extinction subjects presented in Table 3 are in every instance below their Table 2 baseline rates.

Stimulus compounding test results. Table 4 shows that all subjects emitted more responses in $\mathrm{T}+\mathrm{L}$ than tone or light. A mixed treatments (tone, light, and $\mathrm{T}+\mathrm{L}$ ) by groups (extinction vs. punishment in $\overline{\mathrm{T}}+\overline{\mathrm{L}}$ ) ANOVA (see Lindquist, 1953, Type 1 design), of response rate to the three test stimuli yielded a borderline significant groups effect $[F(1 / 6)=6.00$, $\mathrm{p}=.05]$, a significant treatments effect $[F(2 / 12)=25.48, \quad p<.001]$, and a nonsignificant Treatments by Groups interaction $[F(2 / 12)=0.75$, $.6>p>.5]$. More responses were emitted to $T+L$ than tone or light $(\mathrm{p}<.001)$, while tone and light rates were similar $(.3>\mathrm{p}>.2)$. The significant group effect appears due to the fact that the $\overline{\mathrm{T}}+\overline{\mathrm{L}}$ punishment group, which went into the test with a higher avoidance rate, maintained it over the test. However, the

Table 4

Stimulus Compounding Test Results of Experiment II: Responses Per Minute

\begin{tabular}{lcccr} 
& \multicolumn{4}{c}{ Stimulus Conditions } \\
\cline { 2 - 5 } Subject & $\overline{\mathrm{T}}+\overline{\mathrm{L}}$ & \multicolumn{1}{c}{ Tone } & Light & $\mathrm{T}+\mathrm{L}$ \\
\hline & $\overline{\mathrm{T}}+\overline{\mathrm{L}}$ & Punishment & Group \\
121 & .1 & 7.8 & 9.7 & \\
123 & .2 & 11.1 & 8.2 & 13.7 \\
130 & .3 & 2.7 & 5.8 & 6.7 \\
137 & .2 & 3.3 & 5.0 & 10.3 \\
151 & .1 & 2.9 & 3.3 & 5.7 \\
Mean & .2 & 5.6 & 6.4 & 10.3 \\
Mean & & 23.5 & 29.5 & 47.0 \\
Percent & & & \\
& $\overline{\mathrm{T}}+\overline{\mathrm{L}}$ & Extinction & Group & \\
135 & .4 & 2.3 & 2.9 & 5.0 \\
147 & .2 & .9 & 1.4 & 4.8 \\
150 & .7 & 2.5 & 2.8 & 5.5 \\
Mean & .4 & 1.9 & 2.4 & 5.1 \\
Mean & & 19.5 & 24.7 & 55.8 \\
Percent* & & &
\end{tabular}

*Calculated by converting tone, light, and $T+L$ test responses to percentages for each subject and then averaging over subjects. 
nonsignificant Treatments by Groups interaction indicates that the distribution of test responses over tone, light, and $\mathrm{T}+\mathrm{L}$ was comparable between groups.

\section{DISCUSSION}

In the stimulus compounding tests of Experiment I all subjects consistently emitted more responses to tone plus light $(\mathrm{T}+\mathrm{L})$ than to tone or light presented alone. Table 1 even indicates that the relative magnitude of this summative effect increased over the test for all subjects. Figure 1 shows, however, that only S 100 exhibited behavioral contrast during discrimination training. His VI associated tone and light rates increased as his extinction correlated $\bar{T}+\overline{\mathrm{L}}$ rate decreased. Thus, $\mathrm{T}+\mathrm{L}$ controlled additive summation irrespective of behavioral contrast occurring during discrimination training, with roughly the same proportion of test responses emitted to $\mathrm{T}+\mathrm{L}$ by all three subjects.

\section{"Additivity theory of contrast" 2}

The training performance differences between $\$ 100$ who did show contrast and subjects 97 and 98 who did not are characteristic of many studies seeking to demonstrate behavioral contrast with rats (Dickinson, 1973; Freeman, 1971b; Jaffe, 1973; Pear \& Wilkie, 1971). Generally, contrast during discrimination training is less likely to occur in rats barpressing than with pigeons keypecking. The "additivity theory of contrast" postulated by Gamzu and Schwartz (1973) confronts this apparent species difference in this byproduct of discrimination learning. Autoshaping, first reported by Brown and Jenkins (1968), is central to their explanation of contrast.

If a lighted key differentially signals, for a pigeon, the response-independent presentation of food, the pigeon will begin pecking the key though his responses are unnecessary for reinforcement. Moreover, these autoshaped responses are so robust that they persist even when they postpone reinforcement (Williams \& Williams, 1969). Gamzu and Schwartz contend that it is these classically conditioned autoshaped responses resulting from a differential stimulus-reinforcer dependency that sum with those responses maintained by response-reinforcer dependencies in standard multiple schedules that produce contrast. Therefore, contrast occurs during discrimination training in the pigeon because for this species pecking is the consummatory response elicited by the lighted key that signals food and pecking that key is also the operant. Accordingly, when response-reinforcer and stimulus-reinforcer relations do not influence the same class of behavior Schwartz and Gamzu (in press) predict the absence of contrast during discrimination training.

This prediction of the "additivity theory of contrast" is supported by findings that contrast does not occur during discrimination learning with pigeons when, rather than keypecking, treadlehopping (Hemmes, 1973) or

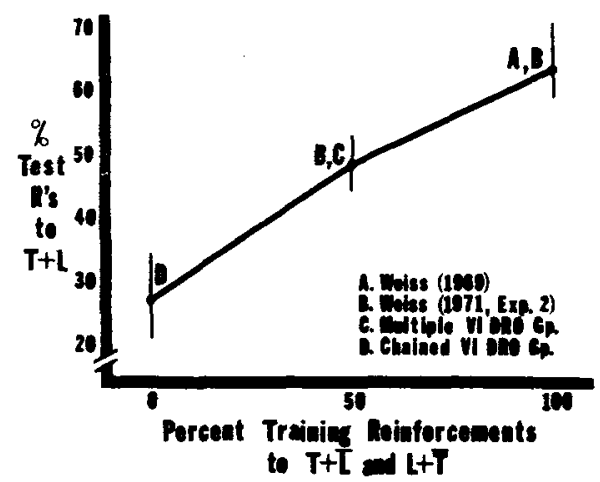

Figure 4. Percentage of stimulus compounding test responses to $T+L$ as a function of the percentage of food reinforcements in training to tone $(T+\vec{L})$ and light $(L+\bar{T})$. Over all reinforcement distributions barpressing was maintained in tone as well as light while $\overline{\mathbf{T}}+\overline{\mathbf{L}}$ controlled response cessation. The vertical lines through each data point indicate the range of all scores represented by that point. See text for additional explanation (from Weiss \& Van Ost, 1974).

barpressing (Westbrook, 1973) is the operant. The discrimination training situation with rats is functionally similar to that Hemmes and Westbrook employed with pigeons, since barpressing and food elicited responses are different. Moreover, the stimulus that signals food is seldom on the manipulandum, and this is a necessary arrangement for autoshaping to occur. Therefore, in most experiments employing rats classically and instrumentally, conditioned responses would not add to produce contrast during discrimination training, and the results of Rats 97 and 98 in Experiment I would be anticipated by an additivity theory. But what of the contrast observed in Rat 100 ? It is possible that the topography of his leverpressing contained characteristics of food elicited responses, such as biting and chewing, that have been autoshaped in rats by Peterson, Akil, Frommer, and Hearst (1972) and Stiers and Silberberg (1974). However, even if this was the case, contrast would not be expected since the stimuli associated with food - tone or chamber illumination - were not on the manipulandum. Thus, the dynamics underlying the contrast of Rat 100 remain unclear with respect to the additivity theory, the closely related "sign-tracking" account of contrast by Hearst and Jenkins (1974), or Terrace's (1972) explanation of this phenomenon considered later.

The contribution of stimulus-reinforcer relations to response distributions during stimulus compounding

According to the additivity theory and the sign-tracking model, stimulus-reinforcer relations, under the appropriately defined conditions, make a significant contribution to the contrast observed in the pigeon paradigm described. It has also been demonstrated that reinforcement differences between baseline schedule components make an important contribution to the distribution of responses during a stimulus compounding test (Weiss, 1969, 1971; Weiss \& Van Ost, 1974). In that 
series of experiments, $\overline{\mathrm{T}}+\overline{\mathrm{L}}$, or its equivalent, controlled response cessation, while tone and light each maintained moderate rates of barpressing. Thus, tone and light were each discriminative for an increase in response for all groups of rats. It was the relative frequency of reinforcement in tone and light compared to that in $\bar{T}+\bar{L}$ that differentiated groups They received $100 \%$, $50 \%$, or $0 \%$ of their food in tone and light.

The $100 \%$ group received all their food reinforcements for responding in tone and light while $\overline{\mathrm{T}}+\overline{\mathrm{L}}$ signaled extinction and came to control response cessation (Weiss, 1969; 1971, Experiment 2). When these animals were confronted with $\mathrm{T}+\mathrm{L}$ in testing, they were solely in the presence of stimuli (a) discriminative for response increase, and (b) that signaled an increase in the reinforcement maintaining that response. Figure 4 shows that under these circumstances $\mathrm{T}+\mathrm{L}$ controlled $62 \%$ of the test responses - powerful additive summation. ${ }^{3}$

The $0 \%$ group in this series of experiments examining the function of relative reinforcement in establishing stimulus control received all their reinforcers in $\overline{\mathrm{T}}+\overline{\mathrm{L}}$ for nonresponding (Weiss \& Van Ost, 1974). These animals were on a chained schedule where responding in tone or light only produced $\overline{\mathrm{T}}+\overline{\mathrm{L}}$. Here $\mathrm{T}+\mathrm{L}$ was composed of stimuli (a) discriminative for response increase, but (b) signaling a decrease in reinforcement, and rate to $\mathrm{T}+\mathrm{L}$ was not different from that to tone or light (Figure 4).

In the tone and light 100\% reinforcement group, response and reinforcement information were compatible during $\mathrm{T}+\mathrm{L}$ - both increasing - while for the tone and light $0 \%$ reinforcement group they were conflicting. If response and reinforcement processes are combining to produce the stimulus compounding test results, a straightforward prediction is possible. When tone and light are discriminative for response increase over $\overline{\mathrm{T}}+\overline{\mathrm{L}}$, but signal no change in reinforcement, $\mathrm{T}+\mathrm{L}$ should control a response output between that of the $100 \%$ and $0 \%$ tone and light reinforcement groups, since only stimulus-response processes would be operating.

This $50 \%$ tone and light reinforcement group was run in experiments reported by Weiss (1971, Experiment 2) and Weiss and Van Ost (1974). Reinforcers were received as frequently in tone and light for responding as in $\overline{\mathrm{T}}+\overline{\mathrm{L}}$ for not responding. For these animals $\mathrm{T}+\mathrm{L}$ was composed of stimuli (a) discriminatave for response increase, but (b) associated with no change in reinforcement frequency from $\overline{\mathrm{T}}+\overline{\mathrm{L}}$. Figure 4 shows that $\mathrm{T}+\mathrm{L}$ controlled $48 \%$ of the test responses for these animals, a percentage in the range intermediate between that produced by the $100 \%$ and $0 \%$ tone and light reinforcement groups.

Figure 4 indicates that the stimulus compounding test is clearly sensitive to the effects of stimulus-reinforcer relations. But it should be appreciated that in this instance these stimulus-reinforcer relations are influencing the strength of an "arbitrary operant" - i.e., an operant that bears no particular relation to the consummatory responses elicited by the food reinforcer. On the other hand, for stimulus-reinforcer relations to be observed through contrast the responses to the reinforcer and the operant response should be of the same class, according to the additivity theory of Gamzu and Schwartz. From this it might be concluded that the findings presented in Figure 4 reveal a mechanism whereby stimulus-reinforcer relations contribute to the control of operant behavior generally, rather than to those operants - such as keypecking - that are confounded by food-elicited respondents. Weiss and Van Ost (1974) have suggested that the Figure 4 curve reveals the operation of the classically conditioned "incentive" process postulated by Mowrer (1960), Spence (1956), Williams (1965), and other learning theorists. Thus, reinforcement differences between schedule components may contribute to both contrast and the distribution of responses during stimulus compounding, as suggested in the introduction. However, in the former instance the operation of these stimulus-reinforcer relations are revealed most readily in responses of the consummatory-response class, while in the latter these relations activate a more general mechanism that influences "arbitrary" operants.

\section{Punishment contrast and response suppression}

Positive behavioral contrast has been shown in the unchanged component of a multiple free-operant avoidance (FOA) schedule when the response-shock interval of the other component was increased (Wertheim, 1965; de Villiers, 1972). In other words, the response rate in the unchanged component varied inversely with the shock rate in the varied component. These findings would lead to the expectation in Experiment II of response increase during tone and light, that remained FOA associated, when $\overline{\mathrm{T}}+\overline{\mathrm{L}}$ was made safe. Figure 2 shows that this was not the case during the initial $\overline{\mathrm{T}}+\overline{\mathrm{L}}$ extinction sessions of Experiment II. Although 100\% of the shocks were now received in the tone and light components, and response rate in $\bar{T}+\bar{L}$ was decreasing for all subjects, over these extinction sessions mean tone and light rates were within 0.4 responses/min of the mean baseline rate. In fact, all animals in the $\overline{\mathrm{T}}+\overline{\mathrm{L}}$ extinction group that satisfied the discrimination criteria of Experiment II had lower tone and light avoidance rates than in their baseline sessions presented in Table 2. These results are consistent with those Appel (1960) reported with rats. Initially, the same FOA schedules operated in the tone-on and tone-off components of his baseline schedule. Then the avoidance schedule was eliminated in one component. During initial discrimination sessions, avoidance rate in the unchanged component was comparable to that of control baseline sessions, but as the discrimination progressed the avoidance rate decreased. This indicates 
that rate reduction in the changed component, and increase in relative shock in the unchanged component, is insufficient to produce contrast in the unchanged component of a multiple FOA schedule. It appears that the avoidance schedules maintained in the varied components of the Wertheim (1965) and de Villiers (1972) studies made a contribution to the contrast they observed in their unchanged avoidance components.

Introducing response-punishment in $\bar{T}+\overline{\mathrm{L}}$ in Experiment II produced significant positive contrast in the unchanged tone and light components (Figure 3A). To date, punishment has been employed in contrast studies primarily to reduce pigeons' responding in one component of a multiple schedule where responding was maintained by positive reinforcement (e.g., Bloomfield, 1966; Brethower \& Reynolds, 1962; Terrace, 1968). In these studies positive contrast was reported in the unchanged component. Similar results on a positive reinforcement baseline were reported with two rats by Coates (1972). Likewise, Lattel and Griffin (1972) produced positive contrast in monkeys by introducing punishment in one component on a multiple FOA schedule. The positive "punishment contrast" produced in Experiment II of the present study is the first time this phenomenon has been reported with rats on an avoidance baseline.

Neither the additivity theory of Gamzu and Schwartz (1973) or Hearst and Jenkins' (1974) sign-tracking model appears to explain the punishment contrast found in Experiment II. Leverpressing is certainly not the unconditioned response to shock in rats (Bolles, 1970), and the discriminative stimuli were not on the manipulandum. Finally, shock occurred to all stimuli in the $\overline{\mathrm{T}}+\overline{\mathrm{L}}$ punishment group, but only to tone and light in the $\overline{\mathrm{T}}+\overline{\mathrm{L}}$ extinction group. This would mean that the stimulus-reinforcer (shock) relation should have been more easily conditioned in the latter subjects that did not show contrast than in the former group that did exhibit contrast. It appears that the contrast produced here is under the control of different variables than the contrast Gamzu and Schwartz, and Hearst and Jenkins, are seeking to explain. Terrace (1972) recently cautioned, "we will not assume that all of these interactions [i.e., examples of behavioral contrast] are manifestations of the same underlying processes..." (p. 205).

Terrace (1972) concludes that response suppression, i.e., an active holding back of responses produced by the schedule operating, in one component of a multiple schedule is sufficient for producing positive contrast in the unchanged component. Figure 2 shows that responding in $\bar{T}+\overline{\mathrm{L}}$ was reduced by $71 \%$ from the prepunishment to the punishment sessions in Figure 3A while this reduction was only about $20 \%$ over comparable sessions where only avoidance extinction was operating in $\overline{\mathrm{T}}+\overline{\mathrm{L}}$ (Figure 3B). Figure 3A also shows that this response-suppression produced contrast was transient, as Terrace suggests it would be, with the avoidance rates of those rats reaching criterion returning to their prepunishment baseline rates. It does appear, nonetheless, that the punishment was exerting an effect on tone and light rates over the number of discrimination sessions seen in Experiment II, since the avoidance rates of the $\overline{\mathrm{T}}+\overline{\mathrm{L}}$ extinction group appeared to go below baseline by their criterion sessions.

Although Terrace's (1972) response-suppression explanation of contrast handles the results of Experiment II very well, it does not so clearly apply to the results of Experiment I, where only S 100 produced contrast. Figure 1 shows that the $\overline{\mathrm{T}}+\overline{\mathrm{L}}$ responding of all three Experiment I rats decreased gradually, at comparable rates, when extinction was programmed in that component. There is no evidence of response suppression as in the $\bar{T}+\overline{\mathrm{L}}$ punishment subjects of Experiment II. Nevertheless, Rat 100 did show a large and sustained rate increase to tone as well as light, while Rats 97 and 98 did not. Neither a response-suppression nor an additivity explanation of contrast appears to apply to this data.

\section{Stimulus compounding tests of Experiment II}

The stimulus compounding test results of Experiment I were essentially replicated in Experiment II. Tone plus light controlled more responding than tone or light presented alone whether or not behavioral contrast occurred during discrimination training. Those subjects who showed contrast summated no more powerfully to $\mathrm{T}+\mathrm{L}$ than did $\overline{\mathrm{T}}+\overline{\mathrm{L}}$ extinction Subjects 135,147 , and 150 , who showed some evidence of induction during discrimination training. Whether response reduction in $\overline{\mathrm{T}}+\overline{\mathrm{L}}$ produced contrast (punishment group) or induction (extinction group) in tone and light rates, the far from significant StimulusCompounding-Test Treatments-by-Groups Interaction indicates that responses were distributed similarly over test stimuli by both groups. If any tendency for superiority in summation is suggested by the data, it is in favor of the $\bar{T}+\bar{L}$ extinction group that showed induction during discrimination training. Since this tendency could be a product, in part at least, of the overall lower response rate of these subjects, it must be viewed cautiously.

\section{CONCLUSIONS}

The results of these experiments did demonstrate consistently that behavioral contrast in tone and light is not a necessary by-product of the discrimination training that leads to a response reduction in $\bar{T}+\bar{L}$, for $T+L$ to produce additive summation during a stimulus compounding test. In both Experiments I and II those animals who showed contrast distributed their compounding test responses similarly to those who did not show contrast. This suggests that it is the 
characteristics of the stimulus control effective immediately preceding the stimulus compounding test, rather than fluctuations in baseline responding occurring prior to that time, during initial discrimination training, that are probably responsible for the test results.

Examination of the terminal baseline training schedules and performance of Experiments I and II reveal many similarities over experiments. These similarities can be seen in the response and reinforcement information conditioned to tone and light prior to testing. In both experiments, tone $(T+\bar{L})$ and light $(\mathrm{L}+T \mathrm{~T})$ controlled response rates substantially higher than the absence of tone and light $(\overline{\mathrm{T}}+\overline{\mathrm{L}})$. In addition, with respect to the reinforcement - positive in Experiment I and negative in Experiment II maintaining responding, $T+\bar{L}$ and $L+\bar{T}$ signaled an increase in reinforcement relative to that in $\bar{T}+\bar{L}$. In Experiment 1 food was received only in $T+\bar{L}$ and $L+\bar{T}$, while in Experiment II practically all shocks were received in $T+\bar{L}$ and $L+\bar{T}$ by both groups. (Table 3 shows that the essentially absolute response cessation controlled by $\overline{\mathrm{T}}+\overline{\mathrm{L}}$ in the punishment subjects prior to testing made this component practically as shock-free for them as it was for the $\overline{\mathrm{T}}+\overline{\mathrm{L}}$ extinction group.) This means that the stimulus that produced additive summation in both experiments - tone plus light $(\mathrm{T}+\mathrm{L})$ - was composed exclusively of stimulus elements that were discriminative for response increase and signaled an increase in the reinforcement maintaining that response. Compare that composite $(T+L)$ to $T+\bar{L}$ and $L+\bar{T}$. $\mathrm{T}+\mathrm{L}$ and $\mathrm{L}+\mathrm{T}$ contained only one element that was discriminative for response increase and was associated with reinforcement increase since $\bar{L}$ and $\bar{T}$, respectively, were common to $\overline{\mathrm{T}}+\overline{\mathrm{L}}$.

Weiss (1972) assumes, in his attentional process model, that a subject is sampling in some fashion the "on" as well as the "off" elements comprising these composite stimuli, and that the behavior resulting to a composite stimulus in these studies would be a "mix" of the habits conditioned to each element. Since, by the end of training, $T+L$ was composed exclusively of stimulus elements (a) discriminative lor response increase, and (b) sigmaling an increase in reinforcement for all subjects, irrespective of whether or not they exlibited contrast, the model would predict additive summation for all subjects. The confirmation of this expectation suggests that the stimulus compounding test results principally reveal the operation of the terminal baseline response associations and reinforcement associations conditioned on these multicomponent free-operant schedules of reinforcement.

\section{REFERENCES}

Appel, J. B. The aversive control of an operant discrimination. Journal of the Experimental Analysis of Behavior, 1060,3, 35-47.
Bloomfield, T. M. Two types of behavioral coutrast in discrimination leaming. Joumal of the Experimental Analygis of Behavior, 1966,9,155-161.

Bolles, R. C. Species specific defense reactions and avoidance learning. Psychological Review, 1970, 71, 32-48.

Brethower, D. B., \& Reynolds, G. S. A facilitative effect of punishment on unpunished behavior. Journal of the Experimental Analysis of Behavior, 1962, 5, 191-109.

Brown, P. L., \& Jenkins, H. M. Auto-shaping of the pigeon's key-peck. Journal of the Experimental Analysis of Behavior, 1968, 11, 1-8.

Coates, T. J. The differential effects of punishment and extinction on behavioral contrast. Psychonomic Science, $1972,27(3), 146-148$.

de Villiers, P. A. Reinforcement and response rate interaction in multiple random-interval avoidance schedules. Joumal of the Experimental Analysis of Behavior, 1972, 18, 499-507.

Dickinson, A. Septal lesions in rats and the acquisition of free-operant successive discriminations. Physlology and Behavior, $1973,10,305-313$.

Emurian, H. H., Weiss, S. 3. Compounding discriminative stimuli controlling free-operant avoidance. Journal of the Experimental Analy gis of Behavior, 1972, 17, 249-256.

Freeman, B. J. Behavioral contrast: Reinforcement frequency or response suppression. Prychological Bulletin, 1871, 75. 347-356. (a)

Freeman, B. J. The role of response-independent reintorcement in producing behavioral contrast effects in the rat. Learning and Motivation, 1971, 2, 138-147. (b)

Gamzu, E., \& Schwartz, B. The maintenance of key-pecking by stimulus-contingent and response-independent food presentation. Journal of the Experimental Analyds of Behavior, 1973, 19,65-72.

Hearst, E., \& Jenkins, H. M. Sign-tracking: The stimulus-reinforcer relation and directed action. Animal Learning \& Behavior, 1974, 2 (Monograph Supplement, 49 pp.).

Hemmes, N. S. Behavioral contrast in pigeons depende upon the operant. Journal of Comparative and Physlological Pay chology, 1973, 85, 171-178.

Jaffe, M. L. The effects of lesions in the ventro-medial nucleus of the hypothalamus on behavioral contrast in rats. Physological Psy chology, 1973, 1, 191-198.

Lattal, K., \& Griffin, M. Punishment contrast during troo-operant avoidance. Joumal of the Experimental Analysis of Behavior, $1972,18,509-516$.

Lindquist, E. F. Design and analysis of experiments in psychology and education. Houghton Mifflin, 1963.

Mowrer, O. H. Learning theory and behavior. New york: $w$ uey, 1960.

Pear, J. J., \& Wilkie, D. M. Contrast and Induction in rate on multiple schedules. Journal of the Experimental Analy sis of Behaviox, 1971, 15, 289-296.

Peterson G Ackil J, E. Frommer, G. P. Hearst, E. $\mathbf{3}$. Conditioned approach and contact behavlor toward denals for tood or brain-stimulation rainforcement. Science, 1872, 177. 1009-1011.

Rey nolds, G.S. Behavioral contrast. Journal of the Experimental Analysis of Behavior, 1961, 4, 57-71.

Schwartz, B, \& Gamzu, E. Pavlovian control of operant behavior: An analysis of autoshaping and of interactions between multiple schedules of reinforcement. In $W$. Honig \& J. E. R. Staddon (Eds.), Operant behavior II. New York: Prentice-Hall, in press.

Spence, K. W. Behavior theory and conditioning. New Haven: Yale University Press, 1956.

Stiers, M.. \& Silberberg, A. Lever-contact responses in rats: Auto-maintenance with and without a negative response-reinforcer dependency. Joumal of the Experimental Analysis of Behavior, 1974, 22, 497-506.

Terrace, H. S. Discrimination learning, the peak shift and behavioral contrast. Journal of the Experimental Analysis of Behavior, 1968, 11, 727-741.

Terrace, $H, S, B y$-products of discrimination learning. In $G, H$. Bower (Ed.), The psychology of learning and motivation. (Vui. 5). New York: Academic press, 1972, 195-265.

Weiss, $S$. J. Attentional processes along a composite stimulus continuum during free-operant summation. Journal of Experimental Psychology, 1969, 82, 22-27.

Weiss, S. J. Discrimination training and stimulus compounding: Consideration of non-reinforcement and response differentiation consequences of $s \Delta$. Journal of the Experimental Analy sis of Beh avior, 1971, 15, 387-402.

Weiss, S. J. Stimulus compounding in free-operant and classica) conditioning: $A$ review and analysis. Psychological Bulletin, $1972,78,189-208$.

Weiss, S. J., \& Van Ost, A. L. Response discriminative and reinforcement factors in stimulus control of performance on multiple and chained schedules of reinforcement. Learning and Motivation, 1974, 5, 459-472. 
Wertheim, G. A. Behavioral contrast during multiple avoidence schedules. Joumal of the Experimental Analysis of Behavior. $1965,8,269-278$

Westbrook, R. F. Failure to obtain positive contrast when pigeons press a bar. Journal of the Experimental Analysis of Behavior, 1973, 20, 499-510.

Williams, D. R. Classical conditioning and incentive motivation. In W. F. Prokasy (Ed.), Classical conditioning. New York: Appleton-Century-Crofts, 1965.

Williams, D. R., \& Williams, H. Automaintenance in the pigeon: Sustained pecking despite contingent non-reinforcement. Journal of the Experimental Analysis of Behavior, 1969, 12 511-520.

\section{NOTES}

1. The reader should note that $\$ 137$, who was initially assicined to the $T+\tau$ extinction croup, was subsequently transferred to the $\overline{\boldsymbol{T}}+\bar{L}$ reaponsenpunishment group. This decision was made because he was, after 30 sesion of extinction in $\overline{\mathrm{T}}+\overline{\mathrm{L}}$, satisfy ing discrimination criterion 1 but not 2. To salvage him, his $\overline{\mathrm{T}}+\overline{\mathrm{L}}$ contingency was changed to response punishment. Thereafter he satisfied both criteria within eight sessions.
2. The author wishes to thank Drs. Elkan Gamzu and Barry Schwartz for supplying him with a prepublication copy of their paper "Pavlovian control of operant behavior: An analysis of autoshaping and of interactions between multiple schedules of reinforcement." See Schwartz and Gamzu (in press).

3. It should be recognized that the terminal training baseline of these tone and light $100 \%$ reinforcement groups were basically similar to that in Experiment 1. However, 7\% more responses were controlled by $T+L$ in these experiments then the $55 \%$ average of the subjects in Experiment $I$. That $T+\bar{I}$ maintained generally less responding in the Weiss $(1969 ; 1971$ Experiment 2) studies than in Experiment I probably contributed to this difference. The greater effectiveness of the discrimination training in the former experiments was most likely due to the fact that discrimination training began very soon after the acquisition of barpressing rather than after the extensive nondifferential reinforcement Experiment I subjects received to tone, light, and $\bar{T}+\bar{L}$.

(Received for publication July 24, 1974.

Second revision received April 29, 1976.) 